\title{
Dilithium 2-aminoterephthalate as a negative electrode material for lithium-ion batteries
}

\section{Stéven Renaulta*, Viorica Alina Oltean ${ }^{\mathrm{a}}$, Mahsa Ebadia ${ }^{\mathrm{a}}$, Kristina Edström ${ }^{\mathrm{a}}$ and Daniel Brandell}

${ }^{a}$ Department of Chemistry - Ångström Laboratory, Uppsala University, Box 538, 75121 Uppsala, Sweden

* Corresponding author. E-mail: steven.renault@kemi.uu.se

\begin{abstract}
This work presents the synthesis and characterization of a novel organic Li-battery anode material: dilithium 2-aminoterephthalate $\left(\mathrm{C}_{8} \mathrm{H}_{5} \mathrm{Li}_{2} \mathrm{NO}_{4}\right)$. When investigated in Li half-cells, the resulting electrodes show stable capacities around ca. $180 \mathrm{mAh} \mathrm{g}^{-1}$ and promising rate capabilities, with battery performance at $500 \mathrm{~mA} \mathrm{~g}^{-1}$ and good capacity recovery, despite being an asymmetric compound. DFT calculations indicate a preferential lithiation on carboxylates close to the amino group.
\end{abstract}

Keywords: Organic Electrode Materials; Lithium-ion Batteries; Carboxylates 


\section{Introduction}

The currently rapid expanding market for Li-ion batteries has also highlighted some of the short-comings of the present technology, in terms of technical performance, cost and sustainability. These issues could be challenged by replacing the conventional inorganic electrodes with organic counterparts, not least if the materials are synthesized from biomass. Among the many battery chemistries referred to as "beyond Li-ion", especially the organics can display significantly lower environmental impact [1-4].

The last couple of years have seen a wide range of such organic electrode materials being promoted, both for anode and cathode sides [5-8]. Of these, carboxylates constitute the perhaps most interesting option for negative electrode materials. They generally display low electrochemical potential, have comparatively solubility in the carbonate-based solvents used in Li-battery electrolytes, are often easy to prepare, and possess an overall good gravimetric capacity. Their drawbacks are, on the other hand, that they are electronically low conductivity materials - thereby needing large amount of conductive additive in the electrodes - and it is frequently observed that the initial coulombic efficiency is low with especially large capacity losses during the initial cycles [9-11].

The archetypal carboxylate anode material is dilithium terephthalate 1 (Fig. 1), since Armand and Tarascon first described redox activity in this category of compounds [12]. This displayed a capacity of ca. $300 \mathrm{mAh} / \mathrm{g}$ and moderate capacity fading for more than 50 cycles. Since then, a number of carboxylates have displayed Li-battery functionality [9-23]. In this context, it is interesting to note that the vast majority of these compounds have been symmetric. If crystalline, asymmetric compounds are, on the other hand, likely to form phases with larger free volume than corresponding symmetric counterparts due to limited 
possibilities for close-packing of the molecules. This could, in theory, render better rate performance. But such structures should also generally possess a lower lattice enthalpy due to less strong intermolecular bonds in the structure, which in turn can generate structural instabilities and thereby limited cycling instabilities. It has been shown that functionalization on the benzene ring give strikingly different properties in terms of capacity and voltage for Na-terephthalates 2 [24]. This effect, however, has so far only been observed in Na-based cells, which are known to be less chemically stable and therefore more difficult to fully interpret [8]. In comparison, Li organic salt-based electrodes have shown clear differences in stability in their battery behavior [25]. In this paper, we describe the synthesis, characterization and battery performance of a new compound, dilithium 2-aminoterephthalate 3 (Fig. 1), to further explore these differences and to investigate the electrochemistry of an asymmetric Li-terephthalate salt.

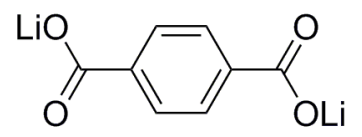

1

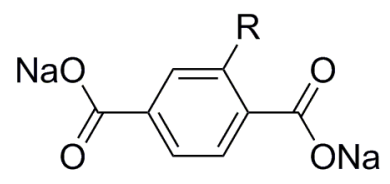

2

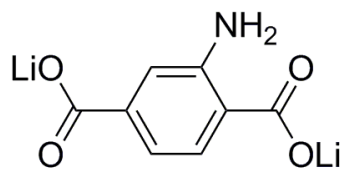

3

$$
\mathrm{R}=\mathrm{H}, \mathrm{NH}_{2}, \mathrm{Br}, \mathrm{NO}_{2}
$$

Fig. 1. Chemical structure of dilithium terephthalate 1,[12] disodium terephthalate derivatives 2 [24] and dilithium 2-aminoterephthalate 3.

\section{Experimental}

\section{Preparation of dilithium 2-aminoterephthalate $\mathrm{C}_{8} \mathrm{H}_{5} \mathrm{Li}_{2} \mathrm{NO}_{4} 3$ :}

In a flat-bottom flask equipped with a magnetic bar, $181.2 \mathrm{mg}(1 \mathrm{mmol})$ of 2aminoterephthalic acid (Sigma Aldrich) and $73.9 \mathrm{mg}(1 \mathrm{mmol})$ of lithium carbonate (Merck) were stirred in $20 \mathrm{~mL}$ of $1 / 1 \mathrm{v} / \mathrm{v} \mathrm{H}_{2} \mathrm{O} / \mathrm{EtOH}$ solution at room temperature for 4 hours. The solution was dried in a ventilated oven at $90{ }^{\circ} \mathrm{C}$ for 16 hours. $198 \mathrm{mg}$ of a brown solid containing $3 \mathrm{wt} \%$ of water was then collected (yield $=99 \%$ ). For electrochemical testing, the 
obtained solid was further dried under vacuum at $100{ }^{\circ} \mathrm{C}$ for 8 hours for complete water removal. $v_{\max }\left(\mathrm{cm}^{-1}\right) 765,832,877,918,1145,1250,1325,1381,1419,1563,1621,3274$, 3335, 3369. ${ }^{1} \mathrm{H}$ NMR $\left(400 \mathrm{MHz}, \mathrm{D}_{2} \mathrm{O}\right): \delta=7.20(\mathrm{~d}, 7.7 \mathrm{~Hz}, 1 \mathrm{H}), 7.27(\mathrm{~s}, 1 \mathrm{H}), 7.70(\mathrm{~d}, 7.7 \mathrm{~Hz}$, 1H) ppm. ${ }^{13} \mathrm{C}$ NMR $\left(100 \mathrm{MHz}, \mathrm{D}_{2} \mathrm{O}\right): \delta=118.1,118.3,123.1,131.0,139.7,147.3,175.5$, $175.7 \mathrm{ppm}$.

\section{Active material preparation}

$137 \mathrm{mg}$ of $\mathrm{C}_{8} \mathrm{H}_{5} \mathrm{Li}_{2} \mathrm{NO}_{4} 3$ were dissolved in a minimum amount of water (ca. $6 \mathrm{~mL}$ ) and 137 mg of carbon super C65 (Imerys) were thereafter added to the clear solution [15]. The resulting suspension was either dried in a ventilated oven at $90{ }^{\circ} \mathrm{C}$ for 16 hours (regular drying method) or sonicated for 30 minutes, frozen using liquid nitrogen and freeze-dried for 24 hours (freeze-drying method) [26]. Mechanical mixing was carried out on a Restch ballmill during 1 hour. The powder and 2 balls (diameter: $20 \mathrm{~mm}$ ) were stowed in a milling container $(55 \mathrm{~mL})$. After transfer in a glovebox, the active material was dried under vacuum at $100{ }^{\circ} \mathrm{C}$ for 24 hours.

\section{Characterisations:}

${ }^{1} \mathrm{H}$ and ${ }^{13} \mathrm{C}$ NMR spectra were recorded at room temperature at $400 \mathrm{MHz}$ and $100 \mathrm{MHz}$, respectively, on a JEOL ECP-400 spectrometer. Chemical shifts $(\delta)$ were expressed in parts per million (ppm) relative to residual $\mathrm{D}_{2} \mathrm{O}$ or an internal standard. A PerkinElmer Spectrum One FT-IR ATR spectrometer was used for IR spectroscopy in the $650-4000 \mathrm{~cm}^{-1}$ frequency range. X-ray diffraction was recorded with a Siemens D 5000 diffractometer using $\mathrm{CuK}_{\alpha}$ radiation. SEM micrographs were obtained using a LEO 1550 instrument. The performances of the electrodes were tested vs. metallic lithium in Swagelok ${ }^{\circledR}$ cells with fiberglass separators soaked with $1 \mathrm{M} \mathrm{LiPF}_{6}$ dissolved in DEC/EC 1/1 (LP40; BASF) electrolyte. Cells were 
assembled in an argon-filled glove box and cycled galvanostatically using an Arbin BT-2043 system at room temperature, while cyclic voltammetry was performed on a VMP BioLogic instrument.

\section{Computational details:}

The dilithium 2-aminoterephthalate salt $\mathbf{2}$ and the corresponding structures after two lithiation steps in the gas phase were optimized by density functional theory (DFT) calculations using the Gaussian 09 package [27] with the B3LYP hybrid functional [28-30] and the $6-311+\mathrm{G}^{*}$ basis set $[31-33]$. For the open shell lithiated molecules, the unrestricted (U) B3LYP method was used. The B3LYP functional has previously been successfully used to describe different molecular systems characterized by ionic interactions [34-36]. Several structural configurations were considered for comparison of their stability. Frequency analysis showed no imaginary frequencies for any geometry. Furthermore, the vibrational frequency analyses were performed for all optimized structures and no imaginary frequencies were observed, indicating that the structures are stable minima on the potential energy surface.

\section{Results and discussions}

The characterisation of the synthesized and dried material is in the Electronic Supporting Information (ESI). From XRD and SEM, it can be seen that the particles display a crystalline structure, with sizes in the 0.1-3 $\mu \mathrm{m}$ range. The NMR and FTIR spectra show all characteristic functionalities of the target compound, with no detectable contaminations. This strongly indicates the successful synthesis of dilithium 2-aminoterephthalate. Residual water was removed according to TGA measurements. Two samples of active material were prepared: the first using a classical drying sequence in an oven, and the second with freezedrying, accordingly to our previous work [26]. Both samples were prepared with in situ 
carbon-coating during synthesis, which we have previously shown to have a beneficial impact on the preparation of water-soluble lithium carboxylates [15].

Fig. 2 shows CV data for this compound in a half-cell during the first three cycles, using a constant potential window between 0.5 and $2 \mathrm{~V}$ vs. $\mathrm{Li}^{+} / \mathrm{Li}^{0}$. The compound presents a generally reversible process with some differences between the two samples. For the freezedried sample, the first cycle only differs slightly from the subsequent ones. Primarily, the first cycle on the reduction side presents a peak at $0.55 \mathrm{~V}$ accompanied by a shoulder at $\sim 0.72 \mathrm{~V}$. This feature can also be seen but with noticeable differences during the following cycles. Since this peak presents a higher intensity, the reaction can possibly be attributed to formation of a Solid Electrolyte Interphase (SEI) layer, a process that is not visible in the next cycles. This indicates a rather limited and stable SEI layer formation, since there are no corresponding signals during subsequent cycles. The oxidation side presents a highly reversible process with virtually no differences between the cycles, suggesting stable electrochemical performance. The main peak is observed at $1 \mathrm{~V}$ followed by a shoulder at 1.6 $\mathrm{V}$ (much more pronounced for the freeze-dried sample due to the smaller particle size), thus displaying a small hysteresis as compared to the reduction processes. The two peaks observed could well correspond to two different lithiation steps, rendering $\mathrm{C}_{8} \mathrm{H}_{5} \mathrm{Li}_{4} \mathrm{NO}_{4}$. The comparatively low potentials seen indicate the possible use of this materials as a Li-ion battery anode. For the regularly dried sample, the first reduction displays a considerably more intense SEI layer formation peak with the shoulder peak barely detectable. The subsequent cycles are more similar to the ones corresponding to the freeze-dried sample with the main differences being slightly less observed polarization (reduction peaks at 0.75 and $0.62 \mathrm{~V}$, oxidation peaks at 0.97 and $1.55 \mathrm{~V}$ ) and a shoulder oxidation peak proportionally less intense. 

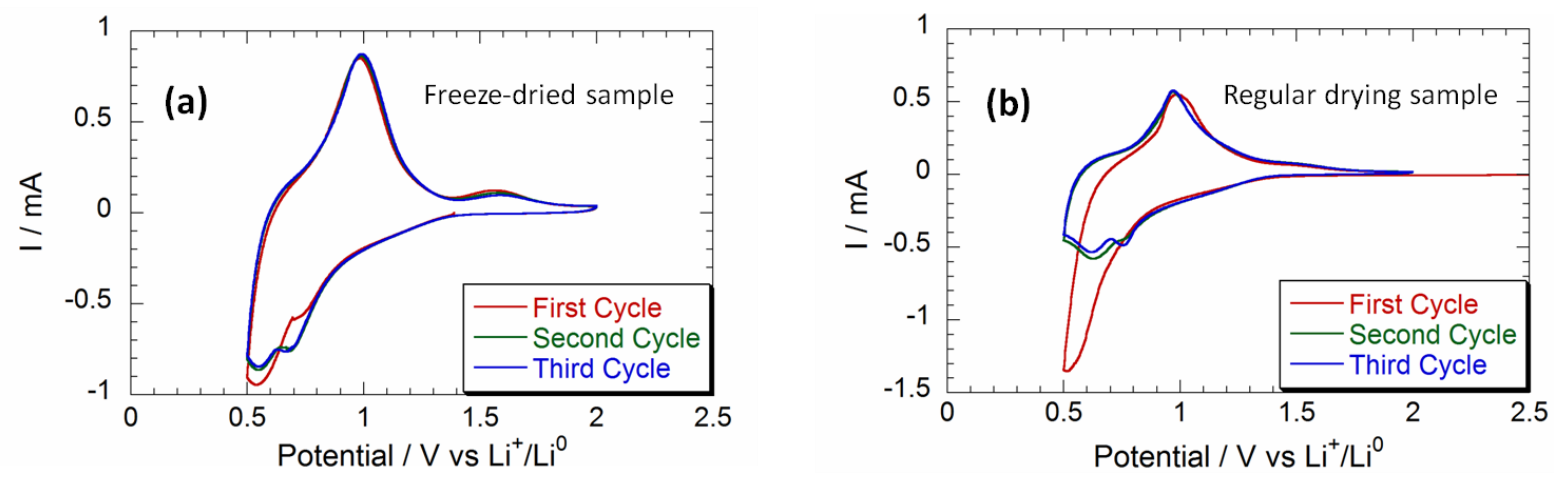

Fig. 2. $\mathrm{CVS}$ of Li half-cells with $\mathrm{C}_{8} \mathrm{H}_{5} \mathrm{Li}_{2} \mathrm{NO}_{4}$ as working electrode scanned between 0.5 and 2 $\mathrm{V}$ in $1 \mathrm{M} \mathrm{LiPF}_{6}$ dissolved in DEC/EC 1/1 (LP40) with the freeze-dried sample a) or regular dried sample b). Scan rate: $0.1 \mathrm{mV} \mathrm{s}^{-1}$.

Fig. 3 shows the first two discharge/charge cycles for dilithium 2-aminoterephthalate $\mathbf{3}$ $v s . \mathrm{Li}$ at a rate of one $\mathrm{Li}^{+}$exchanged in $10 \mathrm{~h}$. The lower current used as compared to the cyclic voltammetry (Fig. 2) gives rise to a shift in potential to slightly higher values during discharge. For the freeze-dried sample, the initial discharge of lithium carboxylate displays a long plateau with an average value of $0.85 \mathrm{~V} \mathrm{vs.} \mathrm{Li}^{+} / \mathrm{Li}^{0}$, in good agreement with the $\mathrm{CV}$ data (Fig. 2), corresponding to a $443 \mathrm{mAh} \mathrm{g}^{-1}$ specific capacity. However, after subtraction of the conductive additive contribution achieved from a blank experiment, the specific capacity corresponding to the active organic material is $237 \mathrm{mAh} \mathrm{g}^{-1}$. This corresponds to 1.7 lithium ions inserted, also with good correlations to the $\mathrm{CV}$ data. The second and subsequent cycles display capacities in the range of ca. $200 \mathrm{mAh} \mathrm{g}^{-1}$ of active material. This drop in capacity is commonly observed for lithium carboxylates, and is normally ascribed to a combination of SEI layer formation, dissolution of active material into the electrolyte or structural changes in the material [9-23]. Compared to other carboxylates, dilithium 2-aminoterephthalate 3 can be considered to cycle stably. It should be noted, however, that the carbon content in the electrodes for this category of materials must be large to display high capacities; if $33 \%$ carbon was used, the capacity drops with more than 50\%. Moreover, the active material 
preparation procedure is also consequential as the sample prepared with a conventional drying sequence displays ca. $40 \%$ capacity drop as compared to the freeze-dried one. Similarly to what was observed in the CVs, the former sample exhibits slightly lower polarization and an almost complete disappearance of the small shoulder observed at $1.4 \mathrm{~V}$ during oxidation with the freeze-dried sample. The first discharge also displays two detectable plateaus that are attributed to a more distinct separation between SEI layer formation and the electrochemical activity of $\mathrm{C}_{8} \mathrm{H}_{5} \mathrm{Li}_{2} \mathrm{NO}_{4}$ considering the disappearance of the first plateau in the subsequent cycles.

Interestingly, the initial coulombic efficiency in the galvanostatic cycling is significantly lower for the freeze-dried compound, which is not indicated in the CV data. This is due to the different cut-off voltages $\left(0.5 \mathrm{~V}\right.$ vs. $\mathrm{Li}^{+} / \mathrm{Li}^{0}$ in the $\mathrm{CV}$, and $0.6 \mathrm{~V}$ during cycling $)$ and the different rates used $(\mathrm{C} / 2.4$ for $\mathrm{CV}$ and $\mathrm{C} / 20$ during cycling). It thus appears that the initial irreversible electrochemical process might have different kinetics as compared to the reversible redox process, in addition to the possible influence of particle morphology and distribution for the two samples. As a consequence, while the initial coulombic efficiency increases for higher C-rates for the freeze-dried sample, the reversible capacity decreased at the same time (as seen in Fig 4a).

It is interesting to note that unlike other aromatic lithium carboxylates - including the closely structurally related dilithium terephthalate $\mathbf{1}$ - dilithium 2-aminoterephthalate $\mathbf{3}$ does not display any capacity that is not related to the conductive additive contribution when cycled below $0.6 \mathrm{~V}$ vs. $\mathrm{Li}^{+} / \mathrm{Li}^{0}$ [22,23]. Its electrochemical behaviour can therefore be explained solely by the redox activity of the carbonyl groups, and no reduction of its unsaturated carbon-carbon bonds - so called "super-lithiation" [23] - is observed. As compared to dilithium terephthalate $\mathbf{1}$, the addition of an amino group seems to have a 
negligible effect on the average redox potential in dilithium 2-aminoterephthalate 3 (ca. $0.9 \mathrm{~V}$ vs. $\mathrm{Li}^{+} / \mathrm{Li}^{0}$ in both cases).
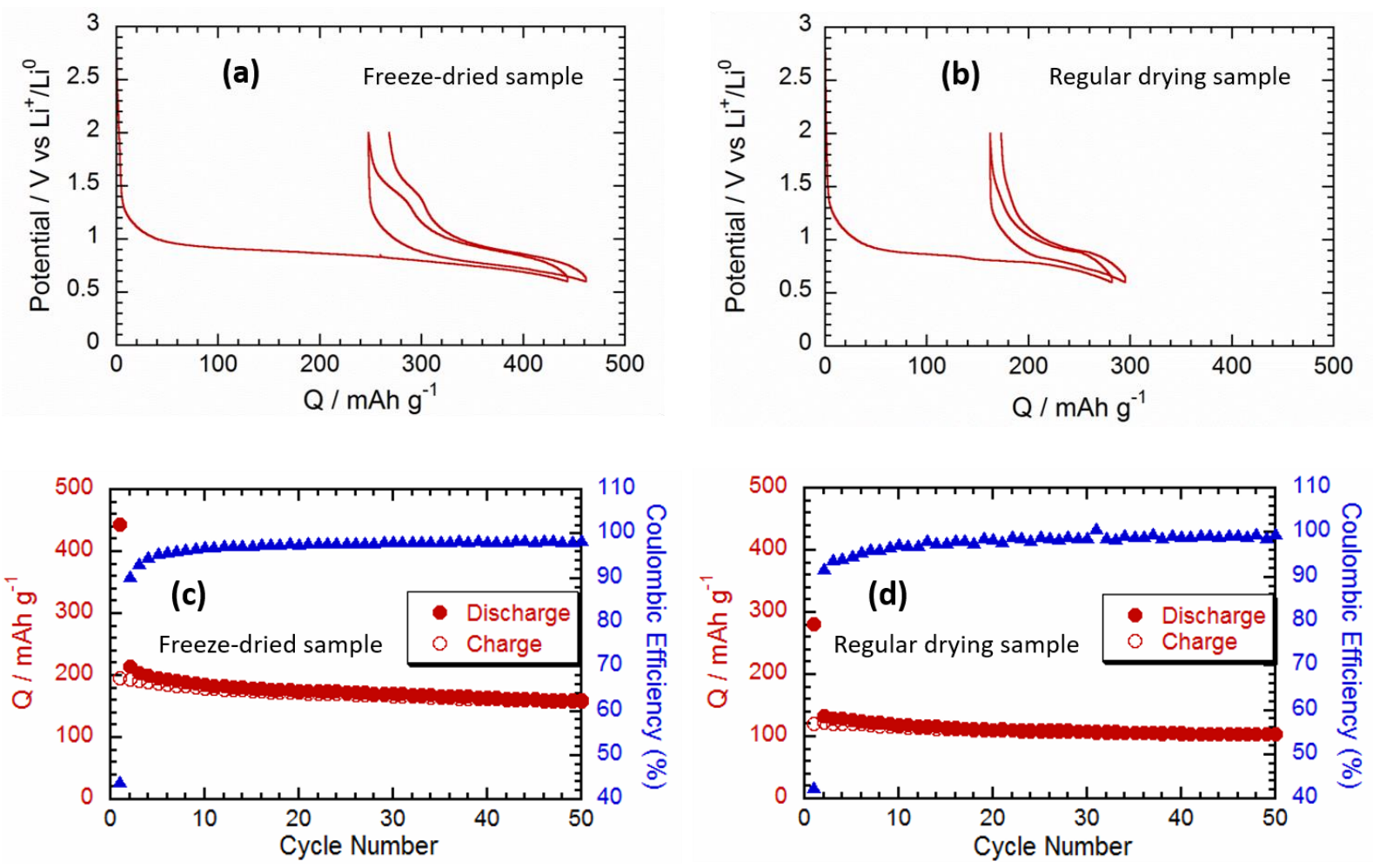

Fig. 3. Electrochemical behaviour of Li half-cells with $\mathrm{C}_{8} \mathrm{H}_{5} \mathrm{Li}_{2} \mathrm{NO}_{4}$ as working electrode cycled galvanostatically between 0.6 and $2 \mathrm{~V}$ at a rate of $1 \mathrm{Li}^{+} / 10 \mathrm{~h}$ in $1 \mathrm{M} \mathrm{LiPF}_{6}$ dissolved in DEC/EC 1/1 (LP40) with the freeze-dried sample a) or regular dried sample b). Corresponding capacity retention curves for the freeze-dried sample c) or regular dried sample d).

Fig. 4 displays the rate performance of the compound. For both samples, an expected loss in capacity can be observed for higher rates, which occurs gradually for the higher currents. However, if cycled at such high currents as $500 \mathrm{~mA} \mathrm{~g}{ }^{-1}$, corresponding to $3.6 \mathrm{Li}^{+}$per amino-terephthalate molecule per hour, the compound still presents good reversibility, and almost all capacity is recovered once the compound is cycled at lower rates again. The fine rate performance can be attributed to good electronical wiring in the electrode, which is not 
often the case for organic electrode materials. This is likely depending on the rather high carbon content in the electrode and its dispersion achieved by liquid-state coating and freezedrying, the latter technique allowing better capacity as compared to a sample dried in a conventional manner independently of the current density $[15,26]$. Yet another factor could be a less dense packing of the material in the crystallites due to the molecular asymmetry.
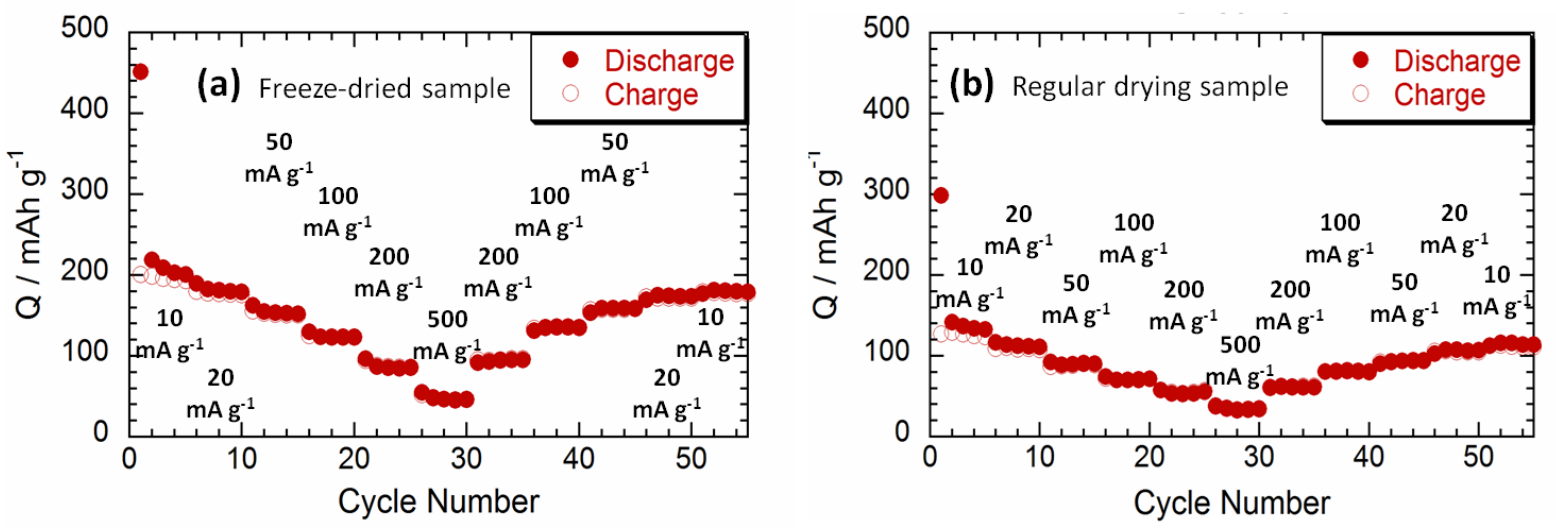

Fig. 4. Rate capability of $\mathrm{C}_{8} \mathrm{H}_{5} \mathrm{Li}_{2} \mathrm{NO}_{4} 2$ cycled between 0.6 and $2.0 \mathrm{~V}$ in $1 \mathrm{M} \mathrm{LiPF}_{6}$ dissolved in DEC/EC 1/1 (LP40) with the freeze-dried sample a) or regular dried sample b).

The asymmetric structure of dilithium 2-aminoterephthalate 2 gives rise to several possibilities for lithiation of the salt. Different conformers of the $\mathrm{C}_{8} \mathrm{H}_{5} \mathrm{Li}_{\mathrm{x}} \mathrm{NO}_{4}(\mathrm{x}=2,3$ or 4$)$ have therefore been investigated by DFT calculations (Supporting Information, Fig. S10 and S11), with the lowest energy configurations for each level of lithiation displayed in Fig. 5. Regarding $\mathrm{C}_{8} \mathrm{H}_{5} \mathrm{Li}_{2} \mathrm{NO}_{4}$ (Fig. 5a), there is a negligible energy difference for the rotation of the carboxylate group in the meta position as compared to the amino group, but a relative increase in energy of $40.0 \mathrm{~kJ} / \mathrm{mol}$ if the lithium is placed between the ortho-carboxylate and the amino group (Fig. S10). 


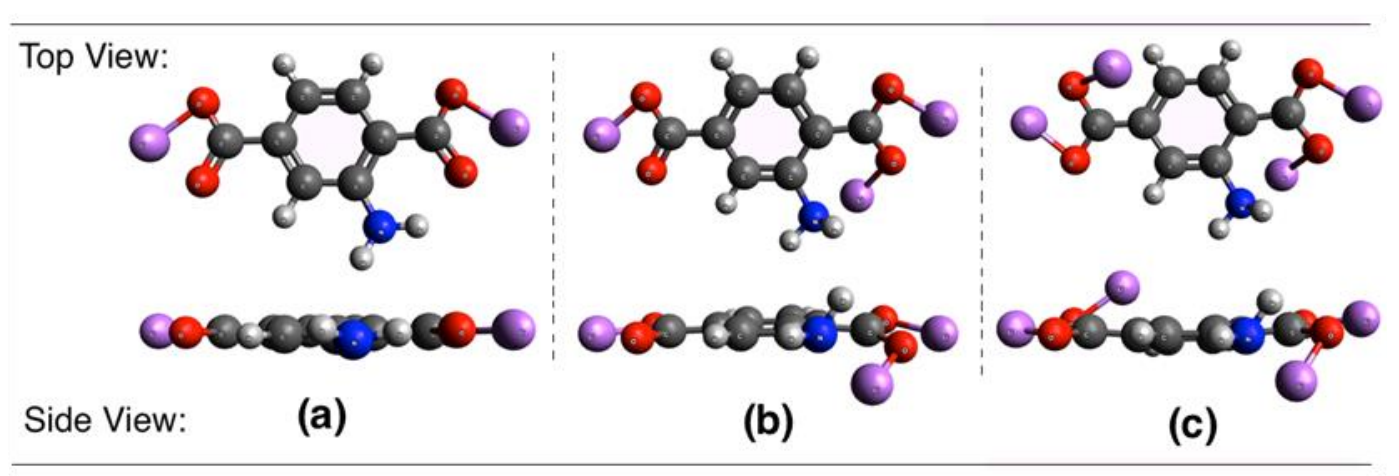

Fig. 5 The three different lowest-energy conformations (top and side views) for different steps of lithiation (a-c) of dilithium 2-aminoterephthalate. Grey = carbon; white = hydrogen; blue = nitrogen; red $=$ oxygen; purple $=$ lithium.

The first lithiation step of the compound seems to occur via reduction of the carboxylate group closest to the amino group (Fig 5b); reduction of the other carboxylate group occurs at a higher relative energy of $29.9 \mathrm{~kJ} / \mathrm{mol}$ (Fig. S11c). The lowest energy is achieved if the lithium atom is placed between the amino group and the ortho-carboxylate. If the lithium is instead oriented away from the nitrogen, the relative energy increases by $26.2 \mathrm{~kJ} / \mathrm{mol}$ (Fig. S11b). These energy differences are significant, indicating that the amino group actually contributes well to stabilize the lithium in the molecular structure, although it should also be noted that the calculations has been performed without the surrounding medium of the salt crystal. The final lithiation step (Fig. 5c) naturally occurs on the unreduced carboxylate group, while maintaining the energetically favourable position for one lithium atom close to the amino group. The energy difference is $\Delta \mathrm{E}=-141 \mathrm{~kJ} / \mathrm{mol}$ at $298.15 \mathrm{~K}$ for this last step of the lithiation reaction.

\section{Conclusions}

A novel potential organic anode material, dilithium 2-aminoterephthalate, has been successfully synthesized, characterized and tested in Li-battery half-cells. Despite its 
asymmetric molecular structure due to the amino substitution on the benzene ring, the capacity and rate performance is similar to several other carboxylates investigated in literature. This amino group substitution also contributes to stabilizing the local environment around lithium during reduction. The use of freeze-drying for active material preparation is shown to give superior performances as compared to conventional drying.

\section{Acknowledgements}

This work has been supported by Formas (Grant number: 2016-00838), the Swedish Foundation for Strategic Research, The Carl Trygger Foundation and the Swedish Energy Agency (Grant number: 39036-1). The computations were performed on resources provided by the Swedish National Infrastructure for Computing (SNIC) at NSC.

\section{References}

[1] Poizot, P.; Dolhem, F. Clean Energy New Deal for a Sustainable World: From Non$\mathrm{CO}_{2}$ Generating Energy Sources to Greener Electrochemical Storage Devices. Energy Environ. Sci., 4 (2011), 2003-2019.

[2] Tarascon, J.-M.; Armand, M. Issues and Challenges Facing Rechargeable Lithium Batteries. Nature, 414 (2001), 359-367.

[3] Armand, M.; Tarascon, J.-M. Building Better Batteries, Nature, 451 (2008), 652-657.

[4] Larcher, D.; Tarascon, J.-M. Towards Greener and More Sustainable Batteries for Electrical Energy Storage. Nat. Chem., 7 (2015), 19-29.

[5] Liang, Y.; Tao, Z.; Chen, J. Organic Electrode Materials for Rechargeable Lithium Batteries. Adv. Energy Mater., 2 (2012), 742-769.

[6] Song, Z.; Zhou, H. Towards Sustainable and Versatile Energy Storage Devices: an 
Overview of Organic Electrode Materials. Energy Environ. Sci., 6 (2013), 2280-2301.

[7] Häupler, B.; Wild, A.; Schubert, U. S. Carbonyls: Powerful Organic Materials for Secondary Batteries. Adv. Energy Mater., 5 (2015), 1402034.

[8] Oltean, V.-A.; Renault, S.; Valvo, M.; Brandell, D. Sustainable Materials for Sustainable Energy Storage: Organic Na Electrodes. Materials, 9 (2016), 142.

[9] Zhao, R.R.; Cao, Y.L.; Ai, X.P.; Yang, H.X. Reversible Li and Na Storage Behaviors of Perylenetetracarboxylates as Organic Anodes for Li- and Na-Ion Batteries. J. Electroanal. Chem., 688 (2013), 93-97.

[10] Deng, Q.; Xue, J.; Zou, W.; Wang, L.; Zhou, A.; Li, J. The Electrochemical Behaviors of $\mathrm{Li}_{2} \mathrm{C}_{8} \mathrm{H}_{4} \mathrm{O}_{6}$ and its Corresponding Organic Acid $\mathrm{C}_{8} \mathrm{H}_{6} \mathrm{O}_{6}$ as Anodes for Li-Ion Batteries. $J$. Electroanal. Chem., 761 (2016), 74-79.

[11] Walker, W.; Grugeon, S.; Vezin, H.; Laruelle, S.; Armand, M.; Wudl, F.; Tarascon, J.-M. Electrochemical Characterization of Lithium 4,4'-tolane-dicarboxylate for Use as a Negative Electrode in Li-Ion Batteries. J. Mater. Chem., 21 (2011), 1615-1620.

[12] Armand, M.; Grugeon, S.; Vezin, H.; Laruelle, S.; Ribière, P.; Poizot, P.; Tarascon, J.-M. Conjugated Dicarboxylate Anodes for Li-Ion Batteries, Nat. Mater., 8 (2009), 120-125.

[13] Wang, S.; Wang, L.; Zhang, K.; Zhu, Z.; Tao, Z.; Chen, J. Organic $\mathrm{Li}_{4} \mathrm{C}_{8} \mathrm{H}_{2} \mathrm{O}_{6}$ Nanosheets for Lithium-Ion Batteries. Nano Lett., 13 (2013), 4404-4409.

[14] Renault, S.; Gottis, S.; Barrès, A.-L.; Courty, M.; Chauvet, O.; Dolhem, F.; Poizot, P. A Green Li-Organic Battery Working as a Fuel Cell in Case of Emergency. Energy Environ. Sci., 6 (2013), 2124-2133.

[15] Renault, S.; Brandell, D.; Gustafsson, T.; Edström, K. Improving the Electrochemical Performance of Organic Li-Ion Battery Electrodes. Chem. Commun., 49 (2013), 1945-1947. 
[16] Fédèle, L.; Sauvage, F.; Bécuwe, M. Hyper-Conjugated Lithium Carboxylate Based on a Perylene Unit for High-Rate Organic Lithium-Ion Batteries, J. Mater. Chem. A, 2 (2014), $18225-18228$.

[17] Yasuda, T.; Ogihara, N. Reformation of Organic Dicarboxylate Electrode Materials for Rechargeable Batteries by Molecular Self-Assembly. Chem. Commun., 50 (2014), 1156511567.

[18] Ogihara, N.; Yasuda, T.; Kishida, Y.; Ohsuna, T.; Miyamoto, K.; Ohba, N. Organic Dicarboxylate Negative Electrode Materials with Remarkably Small Strain for High-Voltage Bipolar Batteries. Angew. Chem., 126 (2014), 11651-11656.

[19] Ogihara, N.; Kishida, Y. Improvement in the Electrochemical Properties of Intercalated Metal-Organic Framework Electrode Materials by Controlling Crystal Growth. Electrochemistry, 83 (2015), 861-863.

[20] Fédèle, L.; Sauvage, F.; Bois, J.; Tarascon, J.-M.; Bécuwe, M. Lithium Insertion / DeInsertion Properties of $\pi$-Extended Naphthyl-Based Dicarboxylate Electrode Synthesized by Freeze-Drying, J. Electrochem. Soc., 161 (2014), A46-A52.

[21] Gottis, S.; Barrès, A.-L.; Dolhem, F.; Poizot, P. Voltage Gain in Lithiated Enolate-Based Organic Cathode Materials by Isomeric Effect. ACS Appl. Mater. Interfaces, 6 (2014), 1087010876.

[22] Lee, H. H.; Park, Y.; Shin, K.-H.; Lee, K. T.; Hong, S. Y. Abnormal Excess Capacity of Conjugated Dicarboxylates in Lithium-Ion Batteries. ACS Appl. Mater. Interfaces, 6 (2014), 19118-19126.

[23] Renault, S.; Oltean, V. A.; Araujo, C. M.; Grigoriev, A.; Edström, K.; Brandell, D., Super-Lithiation of Organic Electrode Materials: the Case of Dilithium Benzenedipropiolate Chem. Mater., 28 (2016), 1920-1926. 
[24] Park, Y.; Shin, D.-S.; Woo, S.H.; Choi, N.S.; Shin, K.H.; Oh, S.M.; Lee, K.T.; Hong,

S.Y. Sodium Terephthalate as an Organic Anode Material for Sodium ion Batteries. Adv. Mater., 24 (2012), 3562-3567.

[25] Mihali, V.A.; Renault, S.; Nyholm, L.; Brandell, D. Benzediacrylates as Organic Battery Electrode Materials: Na versus Li. RSC Adv., 4 (2014), 38004-38011.

[26] Renault, S.; Mihali, V. A.; Brandell, D. Optimizing the Electrochemical Performance of Water-Soluble Organic Li-Ion Battery Electrodes. Electrochem. Commun., 34 (2013), 174176.

[27] Frisch, M. J.; Trucks, G. W.; Schlegel, H. B.; Scuseria, G. E.; Robb, M. A.; Cheeseman, J. R.; Scalmani, G.; Barone, V.; Mennucci, B.; Petersson, G. A. Gaussian 09, Gaussian, Inc.: Wallingford, CT, 2009.

[28] Becke, A. D. Density-Functional Thermochemistry. III. The Role of Exact Exchange. $J$. Chem. Phys., 98 (1993), 5648-5652.

[29] Lee, C.; Yang, W.; Parr, R. G. Development of the Colle-Salvetti Correlation-Energy Formula into a Functional of the Electron Density. Phys. Rev. B: Condens. Matter Mater. Phys., 37 (1988), 785-789.

[30] Vosko, S. H.; Wilk, L.; Nusair, M. Accurate Spin-Dependent Electron Liquid Correlation Energies for Local Spin Density Calculations: a Critical Analysis. Can. J. Phys., 58 (1980), $1200-1211$.

[31] McLean A. D.; Chandler, G. S. Contracted Gaussian Basis Sets for Molecular Calculations. I. Second Row Atoms, Z=11-18. J. Chem. Phys., 72 (1980), 5639-5648.

[32] Krishnan, R.; Binkley, J. S.; Seeger R.; Pople, J. A. Self-Consistent Molecular Orbital Methods. XX. A Basis Set for Correlated Wave Functions. J. Chem. Phys., 72 (1980), 650654. 
[33] Clark, T.; Chandrasekhar, J.; Spitznagel, G. W.; Schleyer, P. V. R.; Efficient Diffuse Function-Augmented Basis Sets for Anion Calculations. III. The 3-21+G Basis Set for FirstRow Elements, Li-F. J. Comput. Chem., 4 (1983), 294-301.

[34] Miao, R.; Jin, C.; Yang, G.; Hong, J.; Zhao, C.; Zhu, L. Comprehensive Density Functional Theory Study on Serine and Related Ions in Gas Phase: Conformations, Gas Phase Basicities, and Acidities. J. Phys. Chem. A, 109 (2005), 2340-2349.

[35] Kolboe, S.; Svelle, S. Does an Ethene/Benzenium Ion Complex Exist? A Discrepancy between B3LYP and MP2 Predictions. J. Phys. Chem. A, 112 (2008), 6399-6400.

[36] Jónsson, E.; Armand, M.; Johansson, P. Novel Pseudo-Delocalized Anions for Lithium Battery Electrolytes. Phys. Chem. Chem. Phys., 14 (2012), 6021-6025. 